\title{
Research on the Optimization and Allocation Management of Teaching Resources for English Teaching
}

\author{
Min Zhao ${ }^{1}$ and Lu Wang $\mathbb{D}^{2}$ \\ ${ }^{1}$ South China Business College, Guangdong University of Foreign Studies, Guangzhou 510545, China \\ ${ }^{2}$ Academic Affairs Office, Jinan University, Guangzhou 510632, China \\ Correspondence should be addressed to Lu Wang; luwang1214@jnu.edu.cn
}

Received 5 January 2022; Revised 27 January 2022; Accepted 12 February 2022; Published 27 February 2022

Academic Editor: Zhiguo Qu

Copyright (c) 2022 Min Zhao and Lu Wang. This is an open access article distributed under the Creative Commons Attribution License, which permits unrestricted use, distribution, and reproduction in any medium, provided the original work is properly cited.

\begin{abstract}
Nowadays, in the era of Internet of Things, there are many kinds of teaching resources and ways to inquire. However, there are many problems in the selection, allocation, and management of teaching resources, and there is insufficient utilization of resources. Through the management of curriculum allocation and teacher resource allocation of teaching resources, this paper knows that since 2005 to 2011, the number of college-level English excellent courses and municipal-level English excellent courses has increased greatly, but the number of national-level English excellent courses is small. In order to strengthen the allocation and management of English teaching resources, the number of national excellent courses should be increased. According to the comparison ratio between the number of students and the number of English teachers in a university, which is $152: 1$, the number of English teachers is small. Among the 67 English teachers, senior titles accounted for $29.9 \%$. Teachers with postgraduate degrees accounted for $22.4 \%$. Ordinary teachers account for $47.7 \%$. In order to improve the allocation of English teachers, ordinary teachers should be trained to improve the allocation of English teachers. By comparing 9-year-old teachers, 5-year-old teachers, and 1-year-old teachers, it is found that most teachers are more inclined to use teaching materials, teaching aids, and multimedia in choosing English teaching resources. And through the SMART teaching resource optimization model to the English teaching resources exist in the lack of funds, lack of administrators, school leaders do not pay attention to, and insufficient use of resources and other reasons for optimization. By comparing the SMART model with general English teaching, the UTAUT model and SICAS model, it can be seen that the model proposed in this paper has greatly improved students' English school ability. Through the analysis of general English teaching and the SMART optimization model, UTAUT model, SICAS model precision, recall rate, F1, AUC, accuracy, and other performance, we know that the SMART model proposed in this paper has the best performance and has a good effect on the optimization of teaching resources in English teaching.
\end{abstract}

\section{Introduction}

In order to improve the effect and level of English teaching in English teaching, we should optimize English teaching resources and manage the allocation of English teaching resources. This paper is aimed at improving the management of the optimization and allocation of teaching resources in English teaching through the management of resource allocation, investigation, and analysis of resources and optimization through the SMART model.
Literature [1] is aimed at English teaching training for teachers, so as to realize the transformation from mother tongue teaching to English teaching. By holding small lectures and online discussion among teachers, the English teaching level is improved, and the language, thoughts, and behaviors of teachers in online discussion are recorded and analyzed. Therefore, according to the analysis, nine related themes are formulated. Literature [2] in the English classroom debate by referring to the relevant literature found that the basic focus is on L1 in L2 teaching. Through 


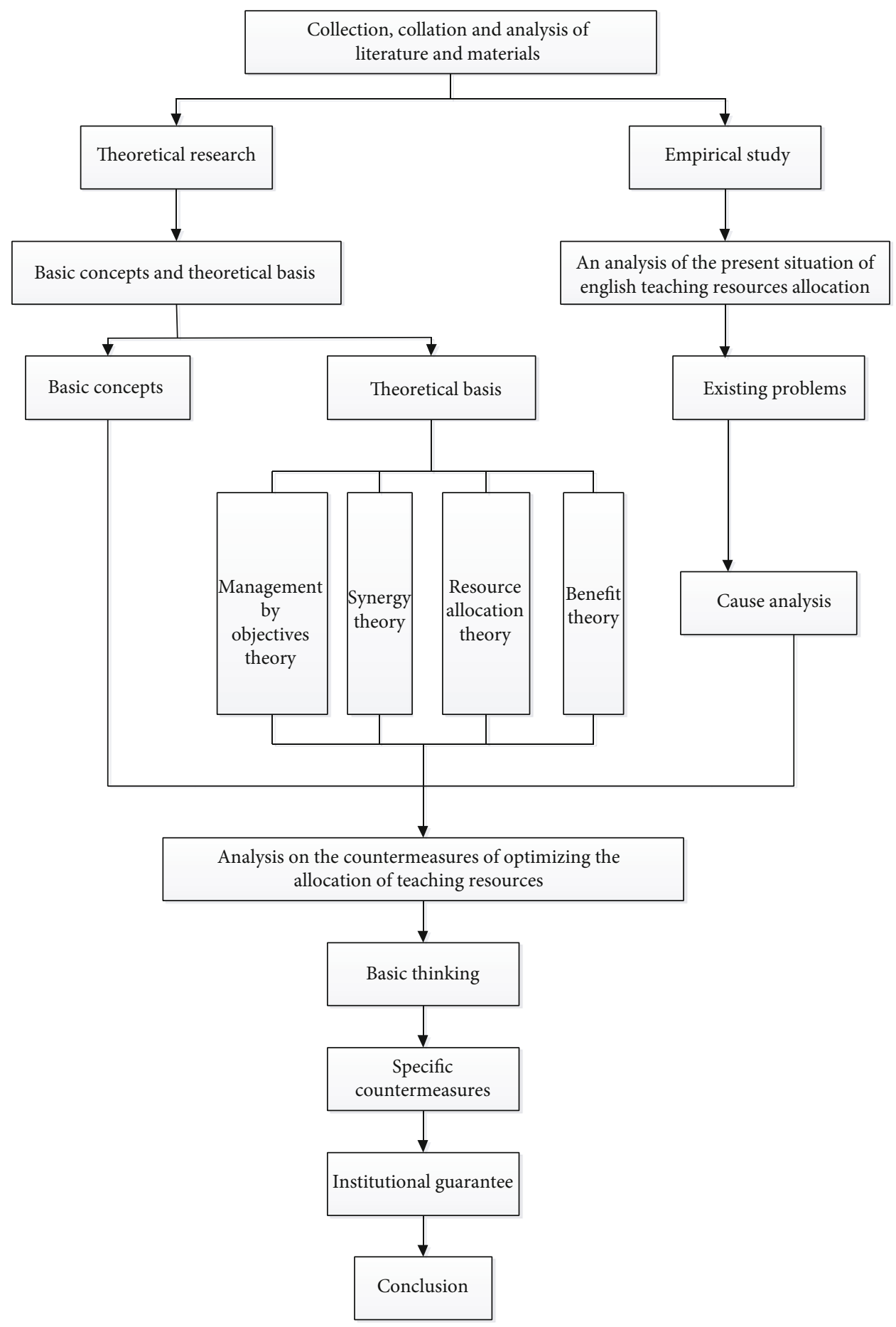

FIgURE 1: Teaching configuration management.

questionnaires and semistructured interviews, this paper collects students' relevant problems and suggestions on English teaching, so as to formulate a more suitable teaching plan to adapt to the specific classroom environment. There is an interest in the content of teaching and the integration of the world's languages due to the situation of second language learning around the world [3]. In order to learn a second language better, we understand the CBI-CLIL viewpoint, review the teaching content, and then summarize and analyze the current situation in order to better carry out second language learning. The author of literature [4], for the study of competitive advantage education, conducted a preliminary experiment by studying and teaching students whose mother tongue is not English. The focus of this activity experiment is the extended teaching of English majors, and the research materials are related learning materials of English majors. In order to solve the problems that cannot be ignored in English teaching [5], schools can improve 


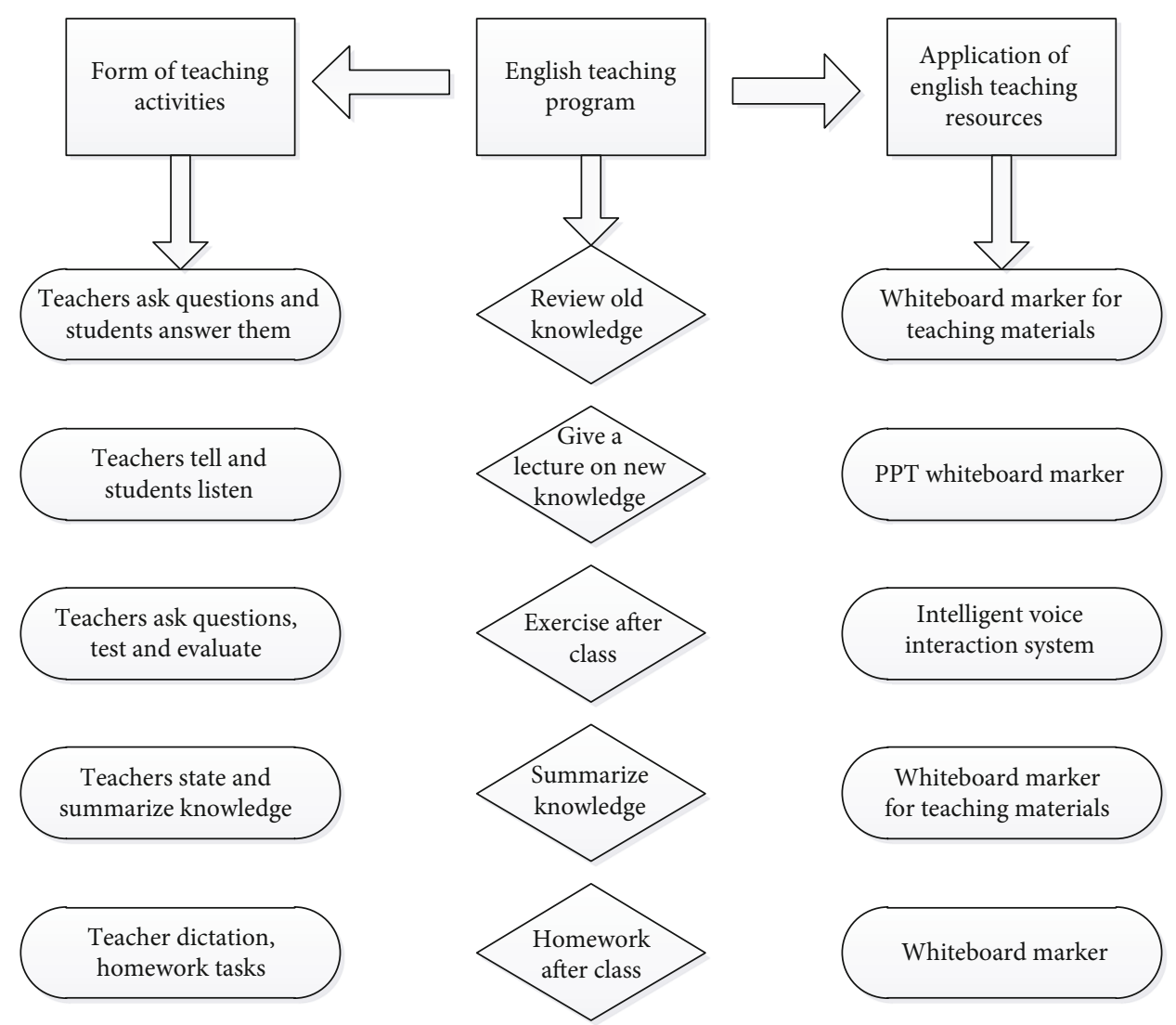

Figure 2: Teaching resource management.

TABLE 1: Curriculum configuration management.

\begin{tabular}{lccc}
\hline Year & $\begin{array}{c}\text { College-level } \\
\text { excellent courses }\end{array}$ & $\begin{array}{c}\text { City-level } \\
\text { excellent courses }\end{array}$ & $\begin{array}{c}\text { National } \\
\text { excellent course }\end{array}$ \\
\hline $\begin{array}{l}\text { In } \\
\text { In }\end{array}$ & 12 doors & 8 doors & 1 door \\
2010 & 15 doors & 8 doors & 1 door \\
In & 12 doors & 8 doors & 1 door \\
2009 & 10 doors & 5 doors & 0 gate \\
In \\
$\begin{array}{l}\text { In } \\
\text { In }\end{array}$ & 8 doors & 5 doors & 0 gate \\
In & 12 doors & 3 doors & 1 door \\
2006 & 7 doors & 3 doors & 0 gate \\
In & & 36 doors & 4 door \\
Total & 76 doors & &
\end{tabular}

English teaching from the aspects of curriculum resources. This paper tries to solve the problems that cannot be neglected in English teaching through the curriculum optimization method of grammar optimization teaching with students as the main part and teachers as the auxiliary part, comprehensive teaching method, and weakening concepts. Literature [6] realizes the optimization of educational

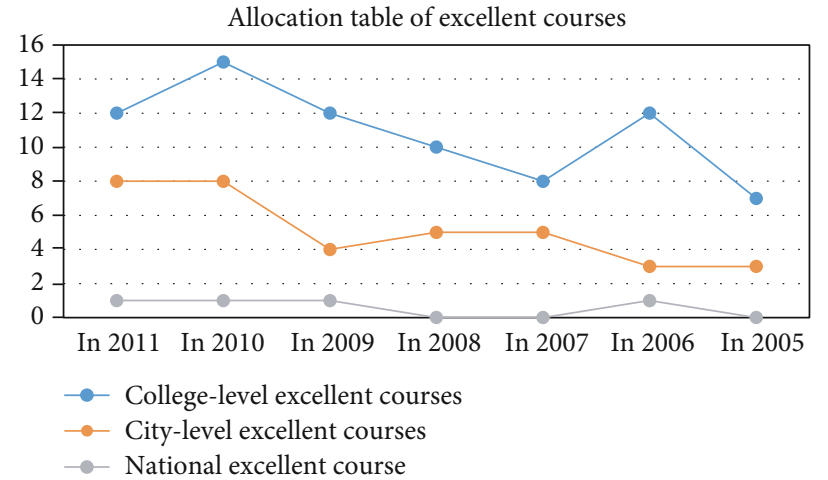

FIgURE 3: Curriculum configuration management.

resources by improving the methods of maximizing efficiency, giving priority to development, sustainable development, and supply. At present, higher vocational colleges are developing rapidly, but there are generally imperfect teaching resources [7]. In order to realize the reform of teaching and promote the group education resources, we will promote the improvement concepts such as integration environment and school-enterprise cooperation to improve the integration of teaching resources. In order to promote the application training of service professionals, this is a common problem faced by higher vocational education at present. In order to reform educational informationization 
TABLE 2: Teacher allocation management.

\begin{tabular}{lccccccc}
\hline $\begin{array}{l}\text { Number } \\
\text { of } \\
\text { students }\end{array}$ & $\begin{array}{c}\text { Number of } \\
\text { English } \\
\text { teachers }\end{array}$ & $\begin{array}{c}\text { Number of } \\
\text { teachers with } \\
\text { senior English } \\
\text { titles }\end{array}$ & $\begin{array}{c}\text { Proportion of English } \\
\text { teachers with senior } \\
\text { professional titles }\end{array}$ & $\begin{array}{c}\text { Number of } \\
\text { teachers with } \\
\text { postgraduate } \\
\text { degree }\end{array}$ & $\begin{array}{c}\text { Proportion of } \\
\text { teachers with } \\
\text { postgraduate } \\
\text { degree }\end{array}$ & $\begin{array}{c}\text { General } \\
\text { English } \\
\text { teacher }\end{array}$ & $\begin{array}{c}\text { Proportion of } \\
\text { ordinary } \\
\text { English } \\
\text { teachers }\end{array}$ \\
\hline 10233 & 67 & 20 & $29.9 \%$ & 15 & $22.4 \%$ & 32 & $47.7 \%$ \\
\hline
\end{tabular}

Proportion of english teachers at all levels

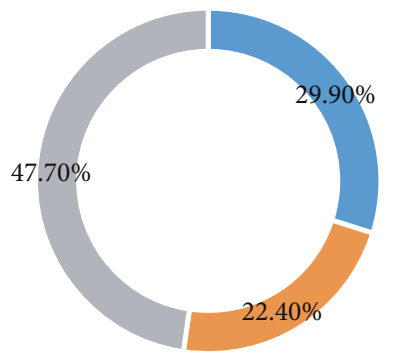

Proportion of english teachers with senior professional titles

Proportion of teachers with postgraduate degree

Proportion of ordinary english teachers

FIGURE 4: English teacher allocation management.

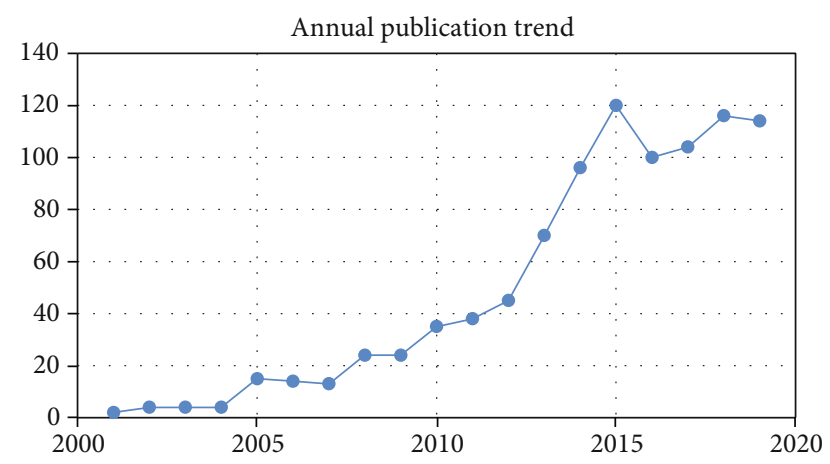

Figure 5: Development of English resources and documents.

and teaching [8], it is necessary to upgrade teaching resources. Literature [9] optimizes distributed resource management in order to effectively control the active and reactive power flow in the power grid. In this paper, the TLBO method is proposed to consider the distributed distribution problem in a variety of scenarios, and at the same time, the internal problems of the TLBO method are improved to reduce losses and improve the overall performance. In order to improve the many deficiencies of teachers' resources and ensure the foundation of education, this paper optimizes the development from two aspects [10]. In order to enable students to master more teaching knowledge in a limited time and lay a good foundation for other subjects, the education of higher mathematics has the nature of task [11]. In order to further improve medicine in many aspects, it is necessary to improve the skills and skills of clinicians in addition to literature inquiry [12]. Through information management applied science to manage a large number of patient data in order to improve the quality of orthopedic surgery, surgeons' time is saved, and the efficiency of surgery is improved. Literature [13] studies the problems of learning resources and the information management system, taking e-reading as an example. This paper discusses the problems and solutions to optimize and manage learning resources and combines learning resources with the learning management system to solve the existing challenges and problems. A perfect talent market can form a complete flow of talents and a high allocation of teachers [14]. Therefore, in order to introduce a large number of high-efficiency talents, colleges and universities need to promote system innovation and talent construction to ensure the stability and basic role of talent resource allocation in the talent market. Literature [15] makes an in-depth study on the educational resources of colleges and universities in order to rationally allocate educational resources and support the teaching and scientific research of colleges and universities. Through rational use, resource sharing, multidevelopment, and so on, we study educational resources, so as to put forward a reliable and efficient scheme to improve teaching resources and management.

\section{English Teaching Resources and Allocation Management}

2.1. English Teaching Allocation Management. The allocation management of English teaching includes the collection and collation of relevant English teaching documents and materials. Theoretical research includes target theory, synergy theory, resource allocation theory, and benefit theory. The empirical research includes the analysis of the current situation of English teaching resources allocation, the analysis of existing problems, and the analysis of the causes of the problems [16]. Finally, it analyzes the countermeasures of optimizing the allocation of teaching resources and sorts out the basic ideas and countermeasures to guarantee the allocation of English teaching resources [17]. Basic ideas and conceptual basis include basic concepts and theoretical basis. Combining the basic concepts with theoretical basis and cause analysis, this paper analyzes the countermeasures for the optimal allocation of teaching resources, as shown in Figure 1.

2.2. English Teaching Resources. When asking questions in the classroom and students answer to review old knowledge, they will use teaching resources such as whiteboard markers; PPT whiteboard markers and other resources will be used when teachers tell and students listen to new knowledge. The intelligent voice interaction system will be used when 
TABLE 3: Use of 9-year-old teachers' resources.

\begin{tabular}{lccc}
\hline Types of teaching resources & Frequency (times) & Duration $(\mathrm{s})$ & Percentage $(\%)$ \\
\hline Teaching materials and teaching aids & 12 & 197 & $9.7 \%$ \\
Multimedia & 11 & 630 & $31.2 \%$ \\
English scene simulation & 3 & 280 & $17.6 \%$ \\
Teacher-student relationship & 10 & 240 & $12 \%$ \\
Total & 36 & 1347 & $70.5 \%$ \\
\hline
\end{tabular}

TABLE 4: Use of resources of teachers with 5 years' teaching experience.

\begin{tabular}{lccc}
\hline Types of teaching resources & Frequency (times) & Duration (s) & Percentage (\%) \\
\hline Teaching materials and teaching aids & 18 & 788 & $48 \%$ \\
Multimedia & 23 & 400 & $26.7 \%$ \\
English scene simulation & 1 & 90 & $7 \%$ \\
Teacher-student relationship & 8 & 180 & $14.3 \%$ \\
Total & 50 & 1450 & $96 \%$ \\
\hline
\end{tabular}

TABLE 5: Use of 1-year-old teachers' resources.

\begin{tabular}{lccc}
\hline Types of teaching resources & Frequency (times) & Duration (s) & Percentage (\%) \\
\hline Teaching materials and teaching aids & 23 & 600 & $32 \%$ \\
Multimedia & 20 & 230 & $30.6 \%$ \\
English scene simulation & 2 & 100 & $4.7 \%$ \\
Teacher-student relationship & 4 & 90 & $4.5 \%$ \\
Total & 46 & 1020 & $56.8 \%$ \\
\hline
\end{tabular}

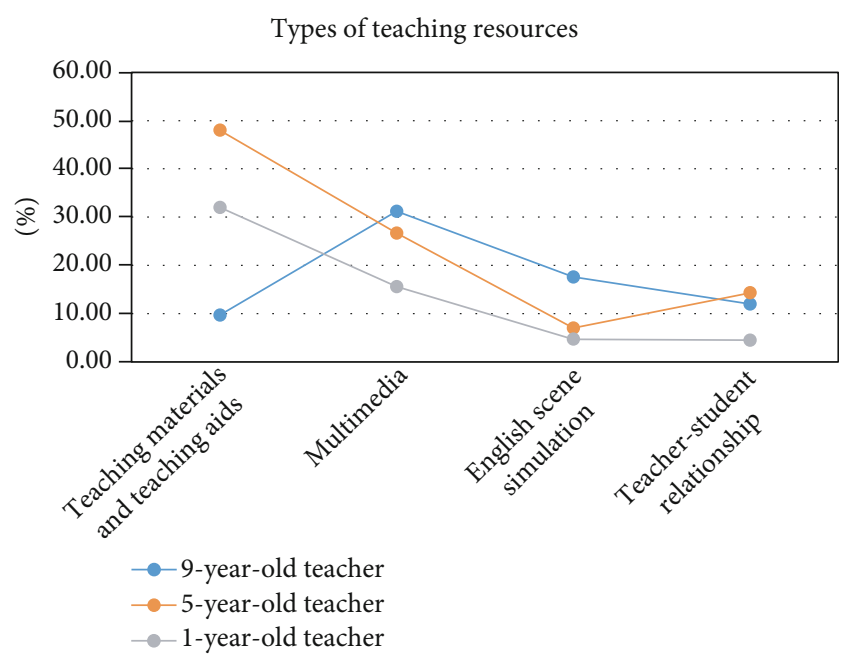

FIGURE 6: Usage diagram of teaching resource types.
Teachers' cognition of teaching resources in english teaching

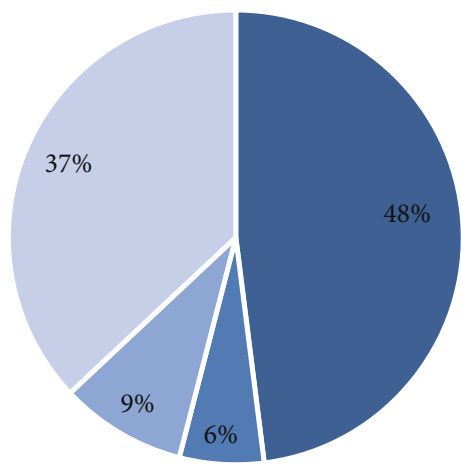

Have a certain degree of understanding

Be very clear

Don't know

I've heard of it and I know little about it

Figure 7: Cognitive map of teaching resources. 


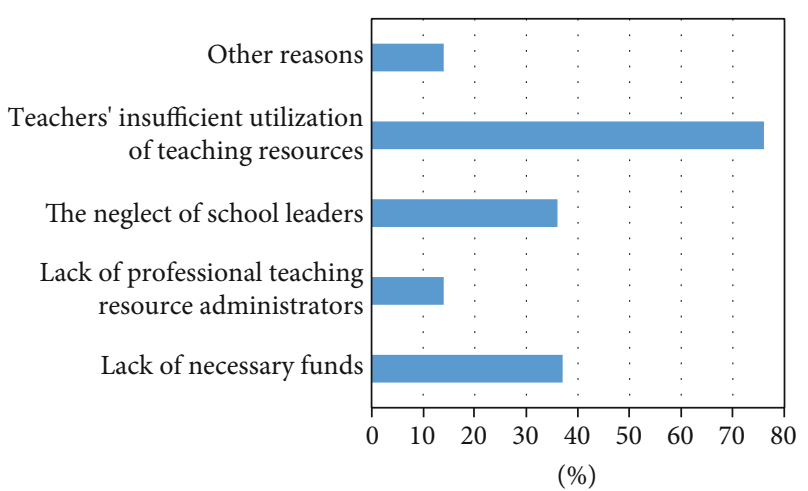

FIGURE 8: Defect diagram of teaching resource use.

teachers ask questions, test, and evaluate after-school practice. When teachers present knowledge to summarize key points, they will use resources such as teaching materials, whiteboards, and markers. Teaching resources such as whiteboard markers will be used for teaching and dictation assignments [18], as shown in Figure 2.

2.3. Optimization of Teaching Resources. In this paper, the SMART model is used to optimize teaching resources. In the SMART model, $S$ is the concreteness of teaching resources in English teaching, $M$ is the measurability of English resources, and A is the sustainability of English teaching resources [19]. $\mathrm{R}$ is the correlation, and $\mathrm{T}$ is the time limit of teaching resources [20]. Through the SMART model, the teaching resources in English teaching are optimized to improve the usability and thoroughness of teaching resources [21].

\section{Correlation Formula}

3.1. Comprehensive Fuzzy Evaluation of English Teaching. Weight set of evaluation index $C=\left(C_{1}, C_{2}, \cdots, C_{n}\right)$ and evaluation set are as follows:

$$
\begin{gathered}
V=\left(V_{1}, V_{2}, \cdots, V_{m}\right), \\
R=\left[\begin{array}{cccc}
r_{11} & \mathrm{r}_{12} & \cdots & \mathrm{r}_{1 m} \\
r_{21} & \mathrm{r}_{22} & \cdots & \mathrm{r}_{2 m} \\
\cdots & \cdots & \cdots & \cdots \\
r_{n 1} & \mathrm{r}_{n 2} & \cdots & \mathrm{r}_{n m}
\end{array}\right] .
\end{gathered}
$$

Vector $B$ is as follows:

$$
B=C \cdot R=\left\{C_{1}, C_{2}, \cdots, C_{n}\right\} \cdot\left[\begin{array}{cccc}
r_{11} & \mathrm{r}_{12} & \cdots & \mathrm{r}_{1 m} \\
r_{21} & \mathrm{r}_{22} & \cdots & \mathrm{r}_{2 m} \\
\cdots & \cdots & \cdots & \cdots \\
r_{n 1} & \mathrm{r}_{n 2} & \cdots & \mathrm{r}_{n m}
\end{array}\right]
$$

The sum of weights is 1 :

$$
C_{1}+C_{2}+\cdots+C_{n}=1
$$

Secondary index values are

$$
\begin{gathered}
C_{i}=C_{i 1}+C_{i 2}+\cdots+C_{i k_{i}}(i=1,2, \cdots, n), \\
\left\{\begin{array}{cc}
C_{1}= & C_{11}+C_{12}+\cdots+C_{1 k_{1}} \\
C_{2}= & C_{21}+C_{22}+\cdots+C_{2 k_{2}} \\
& \cdots \\
C_{n}= & C_{n 1}+C_{n 2}+\cdots+C_{n k_{n}}
\end{array}\right.
\end{gathered}
$$

The weight calculation process is as follows:

The secondary index score $F_{i j}$ is

$$
\begin{aligned}
& F_{i}=F_{i 1}+F_{i 2}+\cdots+F_{i k_{i}}(i=1,2, \cdots, n), \\
& \left\{\begin{array}{l}
F=F_{1}+F_{2}+\cdots+F_{n} \\
F=F_{11}+F_{12}+\cdots+F_{1 k_{1}}+F_{21}+F_{22}+\cdots+F_{2 k_{2}}+\cdots+F_{n 1}+F_{n 2}+\cdots+F_{n k_{n}} .
\end{array}\right.
\end{aligned}
$$

3.2. Teaching Optimization Calculation. Dimensions $D$ and $N$ of decision variables are the total number of students.

$$
\begin{aligned}
X_{i j} & =X_{j}^{\mathrm{min}}+\operatorname{rand} \cdot\left(X_{j}^{\max }-X_{j}^{\min }\right), \\
\text { new } X_{i} & =X_{i}+\operatorname{rand} \cdot(\text { Teacher }-T F \cdot \text { Mean }), \\
\text { new } X_{i} & =\left\{\begin{array}{ll}
X_{i}+\operatorname{rand} \cdot\left(X_{i}-X_{k}\right) & \text { if } f\left(X_{i}\right)<f\left(X_{k}\right) \\
X_{i}+\operatorname{rand} \cdot\left(X_{k}-X_{i}\right) & \text { otherwise }
\end{array} .\right.
\end{aligned}
$$

The particle swarm optimization algorithm is as follows:

Assuming that the lookup space is $T$-dimensional, when there are $H$ particles in the population in the lookup space, the $K$-th particle in the population is expressed as a $T$ -dimensional vector.

$$
\begin{aligned}
V_{k j}^{(t+1)} & =\omega v_{k j}^{t}+s_{1} r_{1 j}\left(p_{k j}-x_{k j}^{t}\right)+s_{2} r_{2 j}\left(p_{b j}^{i}-x_{k j}^{t}\right), \\
x_{k j}^{(t+1)} & =x_{k j}^{t}+v_{k j}^{(t+1)}, \\
v_{t} & =\left[\left(x_{k j} \longrightarrow x_{k j}^{\prime}\right)\right] ; j=1, \cdots, L, \\
p_{i} & = \begin{cases}z_{i} & \text { if } \quad \mathrm{x}_{i}=y_{i} \\
x_{i} & \text { otherwise }\end{cases} \\
v^{(t+1)} & =c_{1} \otimes v^{t} \circ c_{2} \otimes\left(p_{i} \cdot x^{t}\right) \circ c_{2} \otimes\left(p_{g} \cdot x^{t}\right), \\
x^{(t+1)}= & x^{t} \oplus v^{(t+1)} .
\end{aligned}
$$


TABLE 6: SMART model.

\begin{tabular}{lc}
\hline SMART principle & Content \\
\hline S (specific) & Concreteness of English teaching resources \\
M (measurable) & The measurable levels of English teaching resources \\
A (achievable) & Realizability of English teaching resources \\
R (relevant) & The relevance of English teaching resources \\
T (time-limited) & Time limit of English teaching resources \\
\hline
\end{tabular}

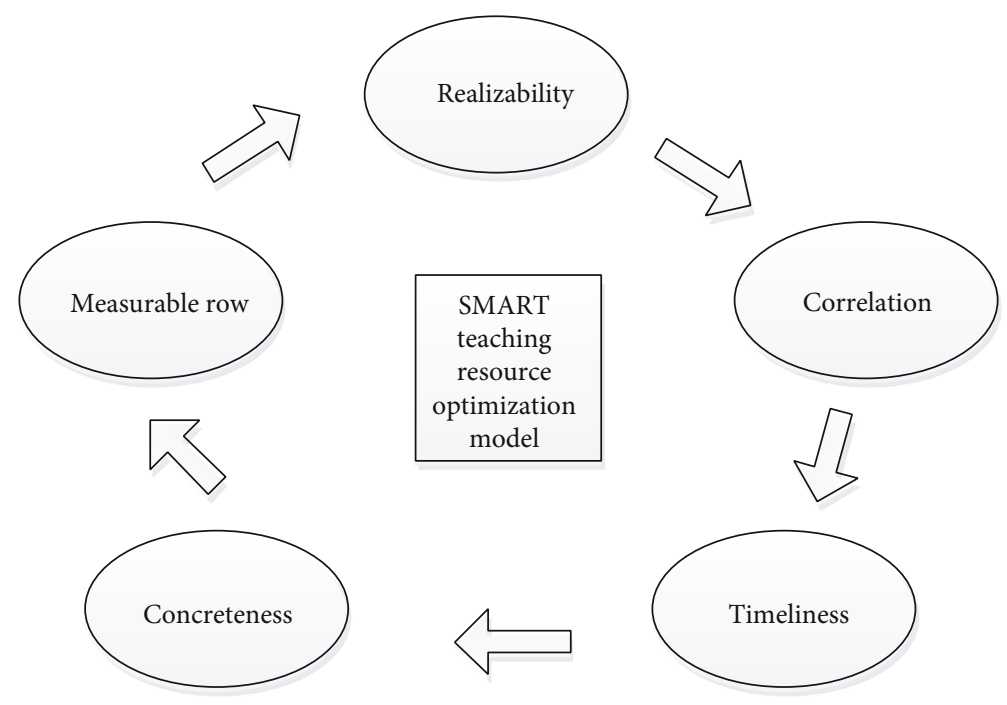

FIgURE 9: SMART optimization model.

TABLE 7: Comparison of model capabilities.

\begin{tabular}{lcccc}
\hline & $N$ & Minimum value & Maximum value & Average \\
\hline LASM model & 30 & 2.3768 & 3.5124 & 2.9446 \\
SMART model & 30 & 2.9758 & 3.9873 & 3.4815 \\
UTAUT model & 30 & 2.5473 & 3.7154 & 3.1313 \\
SICAS model & 30 & 2.6637 & 3.6683 & 3.1660 \\
\hline
\end{tabular}

The improved particle swarm optimization algorithm is as follows:

$$
\begin{gathered}
v_{t}^{k+1}=-c_{1} x_{t}^{k}+c_{2} x_{\text {pbest }, t}^{k}+c_{3} x_{\text {gbest }, t}^{k}, \\
x_{t}^{k+1}=\left\{\begin{array}{ccc}
1 & \text { if } & \rho_{t}^{k+1}<v_{t}^{k+1} \\
-1 & \text { if } & \rho_{t}^{k+1} \geq v_{t}^{k+1}
\end{array}\right.
\end{gathered}
$$

$\rho_{t}^{k}$ is a random value distributed in $[-1,1], v_{t}^{k}$ the value range of speed is $[-1,1], C_{1}$ is the lazy coefficient, $C_{2}$ is the social coefficient, and $C_{3}$ is the cognitive coefficient, where $C_{1}+C_{2}+C_{3}=1[22]$.

The discrete quantum particle swarm optimization algorithm is as follows:

$$
Y=\left[Y_{1}, Y_{2}, \cdots, Y_{Q}\right], \quad X_{i}=\left[x_{t}^{1}, x_{t}^{2}, \cdots, x_{t}^{p}\right]
$$

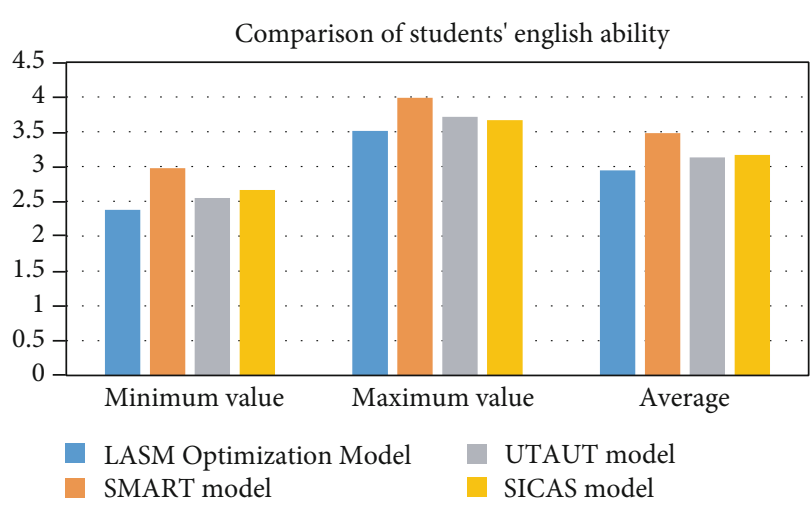

Figure 10: Comparison of students' English ability.

$Q$ is the population size, and $P$ is the number of digits after particle discretization.

$$
\begin{gathered}
v_{\text {pbeat }, t}^{k}=\alpha x_{\text {pbest }, i}^{k}+\beta\left(1-x_{\text {pbest }, t}^{k}\right), \\
v_{\text {pest }, t}^{k}=\alpha x_{\text {gbest }}^{k}+\beta\left(1-x_{\text {gest }}^{k}\right) .
\end{gathered}
$$

The combination optimization of simulated annealing algorithm is as follows: 
TABLE 8: Model performance comparison.

\begin{tabular}{|c|c|c|c|c|c|}
\hline Mode & Precision & Recall rate & $\mathrm{F} 1$ & AUC & Accuracy \\
\hline LASM optimization model & 0.8328 & 0.9324 & 0.8865 & 0.8021 & 0.8547 \\
\hline SMART optimization model & 0.8656 & 0.9497 & 0.9102 & 0.8194 & 0.8623 \\
\hline UTAUT optimization model & 0.8433 & 0.9338 & 0.8897 & 0.8083 & 0.8565 \\
\hline SICAS optimization model & 0.8572 & 0.9412 & 0.8921 & 0.8102 & 0.8601 \\
\hline
\end{tabular}

Performance comparison under intelligent optimization mode

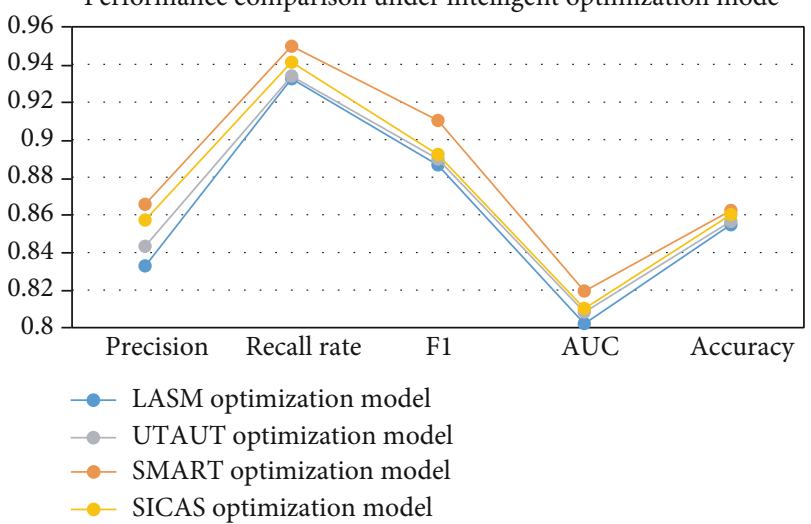

FIgURE 11: Performance comparison diagram in intelligent optimization mode.

$$
\begin{gathered}
r=\exp \left(\frac{E_{i}-E_{j}}{k T}\right), \\
P_{t}(i \Rightarrow j)=\left\{\begin{array}{ll}
1, & f(j) \leq f(i) \\
\exp \left(\frac{f(i)-f(j)}{t}\right) & f(j)>f(i)
\end{array} .\right.
\end{gathered}
$$

3.3. Weight Determination of Resource Allocation Management.

$$
\begin{aligned}
\omega_{i} & =\frac{1}{n} \sum_{j=1}^{n} \frac{a_{i j}}{\sum_{k=1}^{n} a_{k j}}(i=1,2, \cdots, n), \\
\lambda_{\max } & =\frac{1}{n} \sum_{i=1}^{n} \frac{\sum_{j=1}^{n} a_{i j} \omega_{i}}{\omega_{i}}, \\
C I & =\frac{\lambda_{\max }-n}{n-1} .
\end{aligned}
$$

\section{Resource Optimization and Allocation}

\subsection{Allocation and Management of English \\ Teaching Resources}

4.1.1. Curriculum Management. According to the investigation and analysis of teaching curriculum management in English teaching, in 2005, there were 7 college-level excellent courses, 3 municipal-level excellent courses, and no national-level excellent courses. On the whole, from 2005 to 2011, the number of college-level excellent courses and municipal-level excellent courses has increased, including 15 college-level excellent courses in 2010 and 8 municipal- level excellent courses in 2011 and 2010. Compared with 2005, the allocation of English teaching resources has greatly increased. However, as far as the national excellent courses are concerned, there is only one in 2011, 2010, 2009, and 2006 at most. In order to improve the allocation of English teaching resources, we should strengthen the recording of national excellent courses to make English teaching more convenient for teachers and students, as shown in Table 1.

According to the broken line trend in Figure 3, the number of college-level excellent courses is more than that of municipal-level excellent courses and more than that of national-level excellent courses, and the number of national-level excellent courses was 0 in 2005, 2007, and 2008. In order to strengthen the allocation of English teaching resources, we should pay attention to the recording of national excellent courses, as shown in Figure 3.

4.1.2. Allocation of Teaching Staff. As shown in the following table, there are 67 English teachers in a university, of which senior titles account for $29.9 \%$. The proportion of postgraduate education is 22.4. Ordinary English teachers account for the largest proportion of $47.7 \%$. According to the statistics of the number of students and English teachers in a university, the number of students is 10233 , and the number of teachers is 67 , with a ratio of about $153: 1$. The number of English teachers is relatively small compared with the number of students, as shown in Table 2.

As can be seen from Figure 4, in order to improve the configuration management of English teaching, we should start from improving the overall professional titles of English teachers. Teaching training should be given to ordinary English teachers in this school to improve their English teaching experience [23]. In Figure 4, the proportion of ordinary English teachers is $47.7 \%$, followed by the proportion of senior English teachers with 29.9\%, and the proportion of graduate teachers is $22.4 \%$, as shown in Figure 4 .

\subsection{Research on English Teaching Resources}

4.2.1. Present Situation of English Teaching Resources. In order to analyze English teaching resources, this paper studies the publication of English teaching resources research literature from 2001 to 2019. As can be seen from the following chart, the teaching literature of English resources approached 0 in 2001, showed an upward trend from 2002 to 2015 , and reached its peak in 2015, with about 120 documents published. By 2020, about 114 teaching resources documents will be published [24]. With the passage of time, the literature published on English teaching resources has gradually increased, which shows that more and more people pay 
TABLE 9: Model performance comparison.

\begin{tabular}{lccccc}
\hline Mode & Precision & Recall rate & F1 & AUC & Accuracy \\
\hline LASM optimization model & 0.8227 & 0.9223 & 0.8764 & 0.8020 & 0.8446 \\
SMART optimization model & 0.8554 & 0.9396 & 0.9001 & 0.9093 & 0.8522 \\
UTAUT optimization model & 0.8332 & 0.9237 & 0.8796 & 0.8982 & 0.8464 \\
\hline \hline & & SICAS & optimization & model0.84710.93110.8820 \\
\multicolumn{7}{c}{ Comparison of Framework Development Models } & 0.90010.8500 &
\end{tabular}

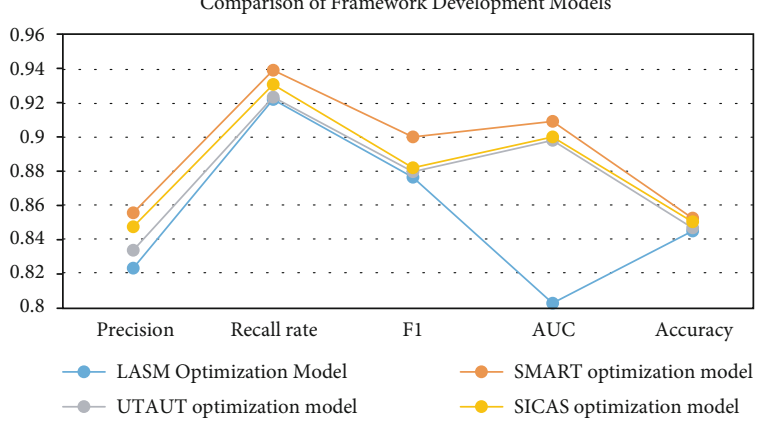

Figure 12: Performance comparison in framework development mode.

more attention to English teaching resources, as shown in Figure 5.

4.2.2. Use of Teachers' Resources. As shown in the following table, through the investigation of the use of English teaching resources by teachers with 9 years' teaching experience, it can be seen that the old teachers who teach for a long time use traditional resources: teaching materials and teaching AIDS the most frequently, 12 times, as shown in Table 3.

According to the teachers who have 5 years' teaching experience, the use of multimedia as a modern English teaching resource is more than 23 times, and the frequency of using traditional teaching materials and teaching AIDS is also more than 18 times, as shown in Table 4 .

Through the analysis of new teachers who only have one year's teaching experience, as shown in the following table, the frequency of using teaching materials and supplementary teaching resources is 23 times, with a percentage of $32 \%$. Multimedia resources are used 20 times, accounting for $30.6 \%$, as shown in Table 5 .

It can be seen from Figure 6 that English teachers with longer teaching experience are less dependent on teaching materials and supplementary teaching resources, use multimedia resources and technology more, and pay more attention to teachers with longer teaching experience in teacher-student relationship resources. For new teachers, the use of teaching materials, teaching AIDS and multimedia resources are low, which shows that new teachers' use of teaching resources in English teaching is not comprehensive and specific, and the use of resources is not in place. Therefore, we should strengthen the use of English teaching resources to better enhance the use of teaching resources, as shown in Figure 6.
4.2.3. Teachers' Cognition of English Teaching Resources. According to the survey of teachers' cognition of teaching resources in English teaching in a university, $48 \%$ of them have a certain degree of understanding of teaching resources, accounting for a relatively large proportion. Among them, $37 \%$ are rarely understood. Unclear accounts for $9 \%$. According to the proportion, there are still many teachers who do not know much about English teaching resources or make insufficient use of them. In view of this situation, English teachers should be trained to understand English teaching resources so as to make better use of English teaching resources, as shown in Figure 7.

4.2.4. Existing Problems. Through analysis, we can see that the proportion of existing reasons from large to small is as follows: teachers' insufficient utilization of teaching resources, lack of necessary funds, school leaders' neglect of teaching resources, lack of teaching resource administrators, and other reasons. In order to improve the lack of teaching resources, this paper optimizes teaching resources in English teaching through the SMART model [25], as shown in Figure 8.

\subsection{Analysis of Teaching Resource Optimization Model}

4.3.1. SMART Optimization Model. In this paper, we use the SMART model to optimize teaching resources in English teaching, where $S$ represents concreteness, $M$ represents measurable lines, A represents realizability, $\mathrm{R}$ represents relevance, and $\mathrm{T}$ represents timeliness. Through the intelligent optimization mode, framework development mode, traditional development mode algorithm for recall rate, accuracy, precision, and other performance tests, the relevant test results can be seen in the three experimental models in this paper, the SMART model proposed in this paper has the best performance, and the performance reaches the best under the intelligent optimization mode, as shown in Table 6.

As shown in Figure 9, the SMART teaching resource optimization model is the mutual transformation and optimization among concreteness, measurability, realizability, relevance, and time limit.

4.3.2. The Influence of English Teaching Resource Optimization on Students. As shown in the following table, comparing the SMART resource optimization model proposed in this paper with the LASM optimization model, UTAUT resource optimization model, and SICAS resource teaching model, it can be seen that when the number of testers is 30 , the average value of SMART model proposed in 


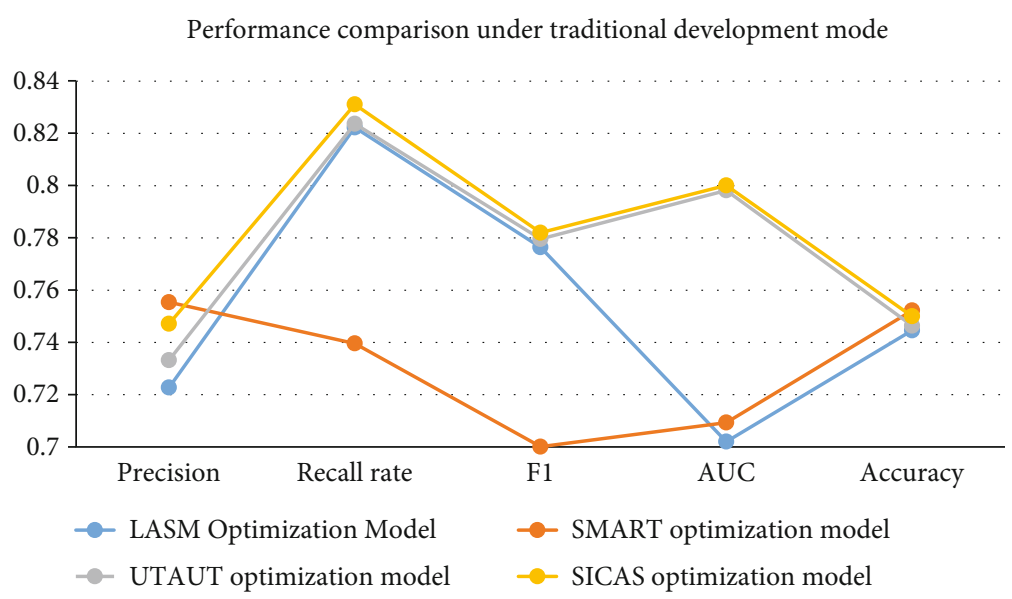

Figure 13: Performance comparison under traditional development mode.

TABLE 10: Model performance comparison.

\begin{tabular}{|c|c|c|c|c|c|}
\hline Mode & Precision & Recall rate & F1 & AUC & Accuracy \\
\hline LASM optimization model & 0.7227 & 0.8223 & 0.7764 & 0.7020 & 0.7446 \\
\hline SMART optimization model & 0.7554 & 0.7396 & 0.7001 & 0.7093 & 0.7522 \\
\hline UTAUT optimization model & 0.7332 & 0.8237 & 0.7796 & 0.7982 & 0.7464 \\
\hline SICAS optimization model & 0.7471 & 0.8311 & 0.7820 & 0.8001 & 0.7500 \\
\hline
\end{tabular}

this paper is 3.4815. The UTAUT model consists of the following: performance expectation $(\mathrm{PE})$ : the degree of personal use of resources to help work; endeavor to expect (EE): the efforts made by individuals to use resources; social influence (SI): the influence of individuals on relevant English teaching resources; and facilitation (FC): help received by individuals in relevant English teaching resources, as shown in Table 7.

As can be seen from Figure 10, when using the SMART teaching resource optimization model proposed in this paper, students' English ability is more prominent.

\subsubsection{Performance Comparison of Optimization Models} under Different Algorithm Models. Intelligent optimization mode problem refers to finding the best scheme or parameter value among many schemes or parameter values under certain conditions, so as to make one or more functional indexes reach the best or make some performance indexes of the system reach the maximum or minimum. Framework development pattern is a semifinished product that provides reusable common structure, which provides great convenience for us to build new applications. For applications, "framework" is the skeleton of the application, and developers can add their own things to this skeleton to build an application system that meets their own needs. The traditional application development mode is as follows: on the one hand, it is necessary to design, develop, and test functions; on the other hand, it is necessary to carry out technology selection, resource preparation, component debugging, continuous construction, version deployment, etc. The whole process cycle is long, and the technology is complex.
(1) Performance Comparison under Intelligent Optimization Mode. Through the performance analysis of the LASM optimization model, SMART optimization model, UTAUT optimization model, and SICCAS optimization model, we can see that the SMART optimization model is the best in English teaching under the performance of accuracy, recall, F1, AUC, and accuracy, and its values are 0.8656, 0.9497, $0.9102,0.8194$, and 0.8623 , respectively. Through data analysis, we can see that the SMART model proposed in this paper has better performance. Accuracy is the percentage of predicted correct results in the total sample. Precision is aimed at the prediction result, the probability that all the predicted positive samples are actually positive samples. Precision rate and accuracy rate look similar, but they are two completely different concepts. Recall is for the original sample, which means the probability of being predicted as a positive sample in the actual positive sample, as shown in Table 8.

Through the performance comparison line chart in Figure 11, we can see that the data of the SMART model is higher than other models. Therefore, the SMART model proposed in this paper should be given priority to the optimization of teaching resources in English teaching, as shown in Figure 11.

(2) Performance Comparison under Framework Development Mode. As shown in the following table, the performance of the four models is compared under the framework development model. Through data analysis, it can be seen that the SMART model proposed in this paper has higher performance, as shown in Table 9. 
(3) Performance Comparison under Traditional Development Mode. As shown in the following table, the performance is compared and tested under the traditional development mode. Through the analysis and comparison of Figures 11-13, it can be seen that the SMART model proposed in this paper has the best performance under the intelligent optimization mode, as shown in Table 10.

\section{Conclusion}

Through the analysis of the allocation and management of English teaching resources and the analysis of English teaching resources, we can see that in recent years, the related methods of English teaching resources have gradually increased, and the use of English teaching resources has gradually increased. But at the same time, there are some reasons such as incomplete use of teaching resources, inadequate management, and insufficient attention. Therefore, this paper proposes the SMART teaching resource optimization model to optimize teaching resources and compares the SMART model proposed in this paper with ordinary English resources, UTAUT model and SICAS model, which shows that the SMART model proposed in this paper has better performance. In the future, the SMART model should be given priority in the optimization of teaching resources in English teaching.

\section{Data Availability}

The experimental data used to support the findings of this study are available from the corresponding author upon request.

\section{Conflicts of Interest}

The authors declared that they have no conflicts of interest regarding this work.

\section{Acknowledgments}

This work was supported by the Foreign Language Special Project of Philosophy and Social Sciences in "The 14th Five-Year Plan" of Guangdong Province: "A Study on the College English Blended Teaching Model from the Perspective of Moral Education" (GD21WZX02-02).

\section{References}

[1] J. Airey, "Talking about teaching in English: Swedish university lecturers' experiences of changing teaching language," Iberica, vol. 2, no. 1, pp. 23-34, 2011.

[2] K. Kieu, "Use of Vietnamese in English language teaching in Vietnam: attitudes of Vietnamese university teachers," English Language Teaching, vol. 3, no. 2, p. 119, 2010.

[3] D. L. Banegas, "Integrating content and language in English language teaching in secondary education: models, benefits, and challenges," Studies in Second Language Learning \& Teaching, vol. 2, no. 1, p. 111, 2016.

[4] Š. Hošková-Mayerová, ““Operational program, education for competitive advantage", preparation of study materials for teaching in English," Procedia-Social and Behavioral Sciences, vol. 15, no. 1, pp. 3800-3804, 2011.

[5] X. C. Zhang, "Dialectical relationships to be considered in English teaching in primary and secondary schools in the new curriculum reform," Curriculum, Teaching Material and Method, vol. 3, no. 1, pp. 112-132, 2007.

[6] L. I. Yu-Cai, "On the optimization of teaching resources in higher occupational education," Journal of Fuling Teachers College, vol. 5, no. 1, pp. 45-58, 2004.

[7] I. Yasim, M. A. Lubis, Z. Noor, and M.Y. Kamarudin, "Vocabulary teaching in English," Language Teaching, vol. 7, no. 2, pp. 11-27, 2016.

[8] N. Sun and M. A. Ning, "Sharing orientation and strategies on the construction of the optimization of teaching resources," Journal of Northeast Normal University, vol. 12, no. 6, pp. 32-43, 2016.

[9] N. Kanwar, N. Gupta, K. R. Niazi, and A. Swarnkar, "Simultaneous allocation of distributed resources using improved teaching learning based optimization," Energy Conversion and Management, vol. 103, pp. 387-400, 2015.

[10] C. Cao and L. I. Lu, "The development and the optimization of the teaching resource of the sports higher education," Journal of Zhanjiang Normal College, vol. 37, no. 10, pp. 123-138, 2012.

[11] M. Fang, H. J. Cai, S. O. Science, and X. S. University, "Optimization and integration of the advanced mathematics' teaching resources," Education Teaching Forum, vol. 47, no. 12, pp. 111-139, 2019.

[12] S. R. Hurwitz and D. C. Slawson, "Should we be teaching information management instead of evidence-based medicine?," Clinical Orthopaedics and Related Research, vol. 468, no. 10, pp. 2633-2639, 2010.

[13] J. Whiting, E. Kartus, and D. Runner, "Challenges of integrating learning resources within the learning management system at Deakin University," in EDUCAUSE in Australasia 03: expanding the learning community, meeting the challenges, pp. 159-171, Adelaide, Australia, 2003.

[14] X. Chen, "Reflections on the allocation of teaching resources in the new-period universities," Journal of Yangzhou University Higher Education Study Edition, vol. 2, no. 1, pp. 132-139, 2003.

[15] W. U. En-Jun, J. F. Cai, and L. Huang, "Management and rational utilization of sports resources in university town," China-USA Business Review, vol. 3, no. 3, pp. 28-34, 2007.

[16] Z. J. Song, L. Yue, and S. X. Hu, "The initial thinking on optimization of teaching content of common geology," Journal of Nanchang College of Education, vol. 57, no. 23, pp. 11341148, 2011.

[17] X. R. Kong, "Research on the optimization of teaching management and resources in university rely on cloud computing," Computer Knowledge and Technology, vol. 37, no. 11, pp. 1145-1159, 2017.

[18] H. U. Chui-Li, "Simulation research of network teaching resources optimization allocation," Computer Simulation, vol. 21, no. 11, pp. 1467-1479, 2017.

[19] A. I. Ning, H. H. Zhou, and D. H. Wang, "Optimization of resources and innovatory experimental teaching," Research and Exploration in Laboratory, vol. 67, no. 3, pp. 117-123, 2008.

[20] J. L. Chen and Z. Di, "Integration and optimization of eresources for foreign language teaching-—a study on 
teaching resources construction in universities," Foreign Language Research, vol. 67, no. 23, pp. 1141-1149, 2014.

[21] Z. Fujian, X. Ke, Z. Dongfang, and Q. Guiying, "Integrating resources, optimizing of resource sharing, and promoting full laboratory opening," Experimental Technology and Management, vol. 57, no. 12, pp. 113-124, 2011.

[22] G. Chen, Q. Pei, and M. M. Kamruzzaman, "Remote sensing image quality evaluation based on deep support value learning networks," Signal Processing: Image Communication, vol. 83, article 115783, 2020.

[23] Y. Lin, "On course-arranging mode in information platform of university teaching management," Journal of Nanjing University of Aeronautics and Astronautics, vol. 56, no. 23, pp. 115127, 2008.

[24] C. Zhong, "Culture teaching in English listening teaching," Journal of Jiaying University, vol. 12, no. 1, pp. 1478-1498, 2006.

[25] S. Soheyli, M. Mehrjoo, and M. Mayam, "Modeling and optimal resources allocation of a novel tri-distributed generation system based on sustainable energy resources," Energy Conversion and Management, vol. 143, pp. 1-22, 2017. 